\title{
THE BRAIN/MIND COMPLEX
}

\author{
AN EPISTEMOLOGICAL APPROACH
}

WILSON LUIZ SANVITO *

\begin{abstract}
SUMMARY - It is stressed that the brain/mind complex constitutes a monolithic system that functions with emergent properties at several levels of hierarchical organization. These hierarchical levels are non-reducible to one another; they are at least three (neuronal, functional, and semantic), and they function within an interactional plan. From the epistemological view-point, the brain/mind complex uses logical and non-logical mechanisms to dea) with day-to-day problems. Logic is necessary for the thinking process, but it is not sufficient. Emphasis is given to non-logical mechanisms; fuzzy logic and heuristics, which allow the mind to develop strategies to find solutions, are analysed.
\end{abstract}

\section{O complexo cérebro/mente: uma abordagem epistemológica}

RESUMO - É ressaltado que o complexo cérebro/mente constitui um sistema monolítico, que funciona com propriedades emergentes em vários níveis de organização hierárquica, irredutíveis uns aos outros. Os níveis hierárquicos são pelo menos três (neuronal, funcional e semântico) e funcionam dentro de um esquema interacionista. Do ponto de vista epistemológico, o complexo cérebro/mente utiliza mecanismos lógicos e não-lógicos para lidar com os problemas do dia-a-dia. A lógica é necessária para o pensamento, mas não é suficiente. Ênfase é dada aos mecanismos não-lógicos, com análise da lógica nebulosa e da heurística que permitem à mente desenvolver estratégias para encontrar soluções.

According to a Piagetian postulate, the human phenomenon is biological in its roots, social in its ends, and mental in its middle. However, some trends of scientific thinking (reflexology, behaviorism, neo-behaviorism) believe that the biological [and human] phenomenon can only be evaluated in its behavioral aspects, within the stimulus-response mechanism, overlooking the brain, which is also called «black box» for being undecipherable. In opposition to this mechanist and reductionist approach are the so-called mentalists, who value the brain mechanisms responsible for human behavior.

Up to the eighteenth century man used to build systems; from the nineteenth century on, he started building models. The model has a scientific basis, whereas the system has a philosophical one. The model is useful as a heuristic device. In other words, analogies are useful, provided one recognizes they are just analogies. They are patterned according to the trend at the time, that is, according to the scientific-technological phase effective then. A kind of Zeitgeist. An example that well illustrates this spirit is the attempt to interpret the functionning of the brain according to the scientific-technological knowledge predominant during each period. Thus, the brain has gone through hydraulic, dioptric, phrenological, geologic, embryologic, and technological models ${ }^{18}$. The latter one was born out of the mechanistic materialism of the seventeenth and eighteenth centuries, through analogies between biological and automatic São Paulo.

* Professor Pleno de Neurologia, Faculdade de Ciências Médicas da Santa Casa de

Dr. Wilson Luiz Sanvito - Disciplina de Neurologia, Faculdade de Ciências Médicas da Santa Casa - Rua Cesário Motta Jr. 112 - 01221 São Paulo SP - Brasil. 
mechanisms. In the automated information era, this type of modeling finds its basis upon cybernetics. The model usually slides into reductionism, and reinains valid only as a research tool. We must reject the model, however, when it is raised to he philosophical status.

The study of the brain is at the same time a fascinating and frightening one. The subject of brain functions certainly requires a pluralist and multidimensional methodology, which encompasses neurobiological, mental, and behavioral aspects, as well as environmental factors. Would the brain have languages to describe itself? That is the question posed by Pribam ${ }^{25} \cdot{ }^{2} \wedge$, which he himself attempts to answer: the human brain, as a decoding instrument that it is, generating languages to describe the signals it sends out and receives, solves the philosophical problem of describing itself.

In modern times, the brain has been looked upon from several different perspectives': (i) as a microphysical system ruled by the determinism principle; (ii) as something similar to an eletronic device, acting according to the rules of automation, regulated by servomechanisms and retroactive circuits, following logico-mathematical principles; (iii) as the primary organ of the mind, the site of memory, thoughts, emotions, intelligence acting by means of neuropsychological constructs. Althoughg they present their own advantages, such models constitute unilateral views and, if considered separately, are unacceptable.

The microphysical model presents the brain as a physico-chemical system subject to causality. This model is accepted by neurophysiologists; it slides into a type of reductionism where human behavior is governed by chemistry laws and, in a last instance, by the laws of physics. The neurocybernetic model is insufficient for the holistic consideration of the brain. However, if the brain is not a computer, nothing prevents it from being looked upon as such. And actually, from many angles, the operating ways (functionalism) of the brain and the computer are alike. The brain receives information data from the internal/external environment, analyses (decodes) them, processes them, synthesizes (re-codes) them, and incorporates them into its memory stock. These data are re-processed and used as needed, by means of searches, plans, strategies, analogies, anticipations, choices, and even heuristic solutions. Therefore, the brain is denotative/connotative, it processes data and formulates concepts; it is at the same time a specialist and a generalist. The brain is capable of facing ambiguous situations with correct solutions and decisions; in computer terminology, it has a behavior which is, at the same time, digital and analogic. The third and last approach favors the neurologic and/or psychological mechanisms, creating a new mythology of the brain, or a psychology without brain. The road in-between is followed by those who favor the neuropsychological constructs.

And what is the mind? The mind is an «entity» slowly built from the evolutionary viewpoint (epigenesis); within the evolutionary-constructivist perspective, the human mind must be considered in its biogenesis, psychogenesis, and sociogenesis. The mental process requires a high-complexity biological substratum, in the sense of hierarchically organizing structures capable of interacting with the environment in a dialectic fashion. The internalization of experience is essencial to the construction of the mind If an experience teaches something, it also causes changes; from this, one gathers that the organism/world interaction is intensely dynamic both ways. Vygotsky ${ }^{3}$ ? rejects the concept of linear development of the individual, and incorporates evolutionary as well as revolutionary changes into his conception; he attributes particular importance to historical-cultural aspects in the formation process of the mind. For Piaget ${ }^{17}$, the mind is dialetic and heuristic, and its process is only submitted to logic at a later stage. Logic simply arranges the elements in the mind, preventing the process from becoming a random one. The cognitive processes - which include logic, heuristics, insights allow man his own construction and the construction of new realities. A good example is the sense of creativity or productivity of the human language: once its acquisition is accomplished, the individual is able to produce or to understand sentences he has never heard before.

\section{THE MIND/BODY PROBLEM}

In the last thirty years, the mind/body problem has been discussed from different angles 5,24,29,30,32^ $j$ conceptual formulations have been presented. The comfortable position of scientific materialism which ignores the possible intervention of conscious forces upon the global functioning of the brain and emphasizes brain processes of physicochemical nature, starts to be questioned. Subjective experiences used to be totally discarted in the approach to brain functioning. But, gradually, the 
terms mentalism and emergence gain a different connotation and begin to be assimilated by neurobiologists. According to Le Moal ${ }^{\wedge}$ subjective experience becomes an emergent property of brain activity, one of its most operational productions, because it brings within itself a causal, organizing, and controlling role of mind functions.

The body/mind problem has been approached from two different views: dualism and monism. For dualists, the physical and the mental are heterogeneous substances: that which is mental is not physical, and vice-versa. The primary dualist trend is interactionism. For Popper \& Eccles ${ }^{24}$, between mental experiences and neural activity there is interaction, but not identity. According to their postulations, the unity of conscious experience depends on mental and not on neural activity, and mental phenomena transcend material phenomena. They hold the position that subjective experience, as an operational mechanism and emergent property of mind activity, plays a causal role in the control of neural functioning. Hardly any form of interactional dualism is compatible with logic. If mind and brain are two completely different substances, it is difficult to conceive how any form of exchange could take place between them.

By adopting a monist position, one faces the risk of reductionism. Although the makeup of live beings presents the same elements of inorganic bodies, its organization originates functions that transcend the physicochemical properties of matter. Within this type of organization, the parts become qualitatively new, and from the new material configuration there emerges a function which cannot be reduced to the sum of its parts. Whenever a whole is dissected into its component parts, the systemic properties are destroyed. Sperry ${ }^{31} .^{32}$ calls himself a mentalist and postulates that mental forces, which emerge from the brain, exert control upon neural activity. Thus, mental entities are molar and configurational; they transcend the physiological, in the same manner that the physiological transcend the mollecular, the mollecular transcends the atomic, and so on, according to an organization connected at multiple levels. Sperry states $^{32}$ : «By calling myself a mentalist, I sustain that subjective mental phenomena are primary realities, causally potent to the extent that they are subjectively lived, differently from their psychochemical elements, to which they are superior and nonreducible». At every moment, the brain is a prodigious generator of emergent phenomena which, by their turn, exert control over the inferior level activities: and the laws of causality depend on a continuous hierarchy at multiple levels within a structured and predetermined continuum. This presupposes that, at each moment when the brain is functioning, at the atomic or conceptual level, processes emerge that are, by their turn, causal and determinist. Thus, for Sperry ${ }^{32}$, the control works in both directions, and it is possible to consider the mind/brain interaction from a monist viewpoint. The $\mathrm{mind} / \mathrm{brain}$ is a complex made of inseparable parts of the same continuous hierarchy.

\section{OPERATIVE WAY OF THE BRAIN/MINI> COMPLEX}

The operative way of the brain encompasses shadows, blind spots, black holes. Initially, it can bs stated that there are no clear boundaries between biological and mental knowledge. It is essential to conceptualize the individual in terms of his adaptive meaning and, in this sense, the biology of behavior is relevant to the structuring of the cognitive/emotional sphere of the brain/mind (B/M) complex. Live beings organize their existence within the need/adversity binomial, and the strategies of adaptation to the environment have a lot to do with evolutionary epistemology. This means that the ways to get to know the world are based on the phylogenesis/ontogenesis; according to Morin the many animal species have developped strategies of simulation, avoidance, astuteness; some of them for the attack, others for defense or escape. Following this reasoning, adaptive behaviors are brought into being by biological evolution within the behavior/adaptation/survival scheme. Thus, the expression biology of knowledge)) used by Riedl28 $\mathrm{j}_{\mathrm{s}}$ justified. Along the evolution process, the individual (through conscious/unconscious learning) incorporates neurotechnologies into his own behavior. A particular strategy may change an unfavorable circumstance into a favorable one. If the behavior acquired through biological knowledge is successful, its re-applicability is maintained. For instance, the fear of certain situations was brought into being by life-preserving strategies. The brain has its own inherent mechanisms; therefore, it can learn by itself, it does not always need the intervention of conscious mechanisms. In its limbic/cognitive aspect, it is equipped with structures which are able to activate the mechanisms of reinforcement of efficient behaviors. Our B/M complex internalizes the organism/world relationship experiences and organizes its cogntive/emotional aspect. Each individual deals with his daily problems using his memory of the species and his own individual memory ${ }^{34}$, When I make a 
decision today, there is a conscious component of manifestation of my free will but the millions of years of selective pressures from the environment, of strategy refinement, and of hits/errors must not be undervalued. However, the theory of knowledge is a biopsychosociocultural whole that cannot be divided into parts.

In relation to this operational model, it is not my intention to proceed with abusive generalizations or magical reductionisms. I think that, in order to try understand [the functioning of] a system, it is necessary to un-build it up to the possible limits, and then try to rebuild it. It must be made clear that the $\mathrm{B} / \mathrm{M}$ complex is formed by structures that can be analyzed at different levels and that are not reducible to one another, in short, it is necessary to understand that there are no parts isolated from the whole, but properties that emerge from the several organization levels. In a microanalysis, the organization of the $\mathrm{B} / \mathrm{M}$ complex can be established in three hierarchical levels: (i) the neuronal level, which has as a substratum the configuration of nerve cells; (ii) the functional level, which is dependent on the organization of neurone groups; (iii) the conceptual level, which is dependent on semantic networks ${ }^{2}$.

For the ones who study the brain, the neurobiology of development has been providing material to get to know the configuration of neurones, their number, the distribution of synapses ${ }^{27}$. Although such configuration is genetically determined, it is influenced by acquired fators, especially the ones of a sociocultural nature. According to Vygotsky ${ }^{37}$, in order to explain behavior it is essential to know the history of behavior. A good example is the organization of the brain for the language function. Since Broca. it is known that there is a specialization of one of the brain hemispheres for that function. However, the brain organization of an individual depends also on cultural factors within his environment. Thus, set in their cultural milieu, the Japanese present a brain organization for language which differs from Western people. The ideographic characters (kanji) are processed in the right hemisphere, while the non-ideographic ones (kana) are processed in the left hemisphere 6,20. However, the studies on the Japanese split brain patients revelead that both Kanji and Kana are processed mainly in the left brain, the role of the right hemisphere in reading and writing of Kanji being almost negligible ${ }^{15}$.

Although the neurone is the anatomofunctional unit of the nervous system, we can only think of the superior brain functions (memory, intelligence, language, etc.) as activities which emerge from the configuration of neurone groups in interaction with the internal/external environment. The nervous system is the interface which allows one to organize the information received, and to transform it into meanings. It is important to think about this functioning level of the $\mathrm{B} / \mathrm{M}$ complex in relation to connections ${ }^{19}$. During the development of the individual there is a variability of brain connections. Although the genes determine the global brain structure, they are not responsible, as time goes on, for the microscopic changes in the connections established between brain cells. After the connections are established, there is a selection which modifies the circuits - but not the models - of such connections. The manner in which an organism interacts with the world and learns to perceive it is what guides the functional anatomy of the brain. The modus operandi of connectional models has been the object of increasingly numerous studies $\left.{ }^{7} »^{9}\right\rangle^{36}$. According to Varela ${ }^{36}$, connectional theories offer elegant models which help to explain a certain number of interesting cognitive faculties, such as fast recognition, and associative memory. Let us examine the specific case of memory. It seems that the memory traces (engrams) rest upon the establishment of specific brain structures and more or less durable networks of preferential activation between cells. This concept was formulated by Hebbe $^{14}$ who described a synaptic mechanism model: the repetition of simultaneous stimulation of two cells would modify the efficiency of the connecting synapses. Stemming from this fact, the so-called connectional models started to be thought out, having as a substratum the modification of properties of the synapses, rather than those of the neurones themselves. From the theoretical viewpoint, this means that the memory trace would be linked to the formation and persistence of a connection network between cells, although none of them contains the information needed to bring about memory. Thus, the memory trace would be present in the network, but absent to the extent that its existence could not be evidenced until the network activation. Therefore, the configurations of the system connections become inseparable from the history of their changes and from the type of task imposed upon them. So, it has become increasingly clearer to neuroscience investigators that the neurones must be studied as members of large groups which constantly appear and disappear along their cooperative interactions; or, each neurone presents multiple and diverse reactions, depending on the context ${ }^{\text {s }}$. The brain is then a highly cooperative system: the concen- 
trated network of interconnections among its constituent elements implies that all takes place there will eventually be a function of all its constituents. The approach is connectional, emergent, self-organizing, associative, and it makes use of dynamic networks 36.

Fodor $^{10}$, for instance, defends a modular functioning of the $\mathrm{B} / \mathrm{M}$ complex, and within this model each module deals exclusively with one type of information, which it receives from certain receptors or from other modules. The module is impervious to cognitive influences, and the result it produces depends only on data flow. The module operates in a compulsory, automatic, and very fast manner. Among the modules there are, besides the ones which deal with several types of sensory information, those which concern themselves with certain kinds of linguistic information (at least the phonologic and syntatic ones). In Fodor's model, besides the receptors and modules, there is a central unit which he calls belief recall system, corresponding grosso moda to the superior cognitive functions (except for language in some of its dimensions). As opposed to the modules, this system would be totally devoid of structure, and each one of its points would be potentially connected to all others. In Fodor's view, this belief recall system will always escape a complete scientific theorization; the cognition program would then, in its purely scientific component, limit itself to the study of modules and of the architecture of the whole. But the central unit would continue being permeated with philosophy.

At the conceptual level, the $\mathrm{B} / \mathrm{M}$ complex works with meanings based on a semantic network. It is the predominantly cognitive sphere of the $\mathrm{B} / \mathrm{M}$ complex. If the functional level presents a computerlike operational mode, the conceptual level is cogitative and deals with symbols within contexts. And how does the B/M complex deal with information at the conceptual level? Let us analyse the specific case of the apple. Initially, the physical qualities of the apple are analyzed and decoded: its shape, color, smell, taste, etc. After this information is processed, we have the attribution of meaning at the semanti network level. The several organization levels of the nervous system permit an analysis which covers the information received through the sense organs (receptors), and the attribution of the several meanings according to the learning/experience/memory awakened by the stimulus within its context. Then the $\mathrm{B} / \mathrm{M}$ complex is prepared to process the information and to attribute meanings according to the context within wich this information is being provided, and according to the mind's cognitive collection. Thus, the apple may be viewed as a delicious fruit, or as the forbidden fruit as mentioned in the Genesis, or as the apple which would have influenced Newton in the formulation of his law of gravity. At this level, the categorization of the stimulus (as a symbol) and the attribution of meaning to the same stimulus in different contexts are important.

\section{THE BRAIN/MIND COMPLEX AND THE LOGIC}

Reportedly, Epimênides from Crete once stated: «A11 Cretans are liers», and so created a problem apparently without solution. This impasse may occur with paradoxes which depend on the use of concepts whose realm of reference includes the concept itself. In the Cretan model, the simple statement - «What I am stating is not true» - generates an intrinsic contradiction: if the statement is true, it is demonstrated that the statement is false; if it is false, we must understantd that it contains the truth. This is the Cretan paradox, brought back to the life in the modern era by Groucho Marx: «It doenfs interest me to belong to a club which is willing to accept me as a member $»^{3}$. These paradoxes have been reduced to mathematical form by Gõdel and Tarski. According to Godel's theorems, a complex formalized system (postulated as an axiom) cannot be self-validated ${ }^{4} .{ }^{12} *^{35} \cdot{ }^{38}$. This means that a logical system of a certain complexity cannot escape its hidden contradictions. Tarski, on the other hand, emphasized the language problem: a semantic system does not have capability to explain itself completely ${ }^{3}$. Symbolic language is used to describe parts of the world and it encounters serious difficulties to describe its own parts. Could the elaboration of a metalanguage remove this obstacle? Such is not the opinion of Morini, for whom the formalized languages cannot constitute a metalanguage in relation to our language.

The mind is a much more encompassing entity [therefore, it transcends the brain], but in order to approach the logical processes of the mind it is imperative to analyse the brain. The brain can be grossly divided into three closely related instances: the vegetative brain (which controls viscera and glands); the limbic brain (responsible for emotional behavior); and the cognitive brain (responsible for logical behavior). Let us isolate from this three-part brain the cognitive brain, which has 
as its substratum the neocortex. The human brain is able to harmonize two functions to a certain extent incompatible: specialization and generalization. Although the brain organization combine specializations and non-specializations, localizations and non-localizations, this organ has a big capacity to integrate all the information processed. However, the brain hemispheres are not functionally equivalent. In general lines, the left brain is logical, deals more with abstract problems, and processes informaiton in a sequential manner. The right brain is more intuitive-emotional, deals more with concrete problems, and processes information in an analogical manner. Our brain internalizes the* experiences of the organism/world relation, and by doing such it organizes its mental sphere. The $\mathrm{B} / \mathrm{M}$ complex deals with information and transforms it into meanings in order to produce behavior programs. These are the informational/computacional aspects of the brain, to which the communicational/cogitational aspects are added. Thus, from Morin's viewpoint 23, wa are computing/cogitative beings.

We are used to hearing that our thinking is logical, and we try to remove from our reasoning whatever goes against the standards of logic. Here we are refering to formal logic, which can be considered a classical form of representing knowledge about the world. Its systematization began with Aristotle and has continued up to the modern logicians. This kind of logic has influenced philosophy in a relevant manner, and has been adopted as a model of human reasoning. In fact, logic is an indispensable tool to make reasoning operational in concrete situations. But could we reduce the human brain to an organ which «metabolizes» information, depends on servomechanisms, and works according to logica-mathematical principles? Definitively not. The B/M complex is an open system which has its own plasticity (with great behavioral variations), and which deals with precision/imprecision, correctness/ambiguity, complete/incomplete, order/disorder; therefore, it has to develop strategies for its organization. These strategies, many of them in the form of incorporation of neurotechnologies, adapt themselves to the animal's behavior along the evolutive process.

Many people claim they see our reasoning marked by logico-mathematical principles. That is because the tactics of organizing mental data has an operative effect upon the provision of the thinking flow (linguistic, logical, numeric algorithms). Logic [and mathematics] identifies itself with the exact sector of our thinking; however, two objections may be raised to this view: first, that the exact model of knowledge is not totally mathematical, because science is not only mathematical; and second, that the relations between the exact and the non-exact sectors of our thinking are equally rich in terms of meaning and philosophical interest". Due to its complexity, thinking requires a multiplicity of logical systems, and even non-logical ones ${ }^{21}$, in mathematics we deal mainly with an axiomatic-like logic, that is, a proposition is demonstrated when deducted from other propositions accepted as true. So, the log co-mathematical reasoning has many tautological characteristics. The human mind cannot be viewed as a deduction machine (a kind of processing gadget for signs/symbols), but it must establish strategies that make it possible to evidence tautologies not perceived initially.

Commonsense knowledge is not always coordinated by the rules of logic. We try to assimilate knowledge by means of logic reasoning, inferences, and by a sequence in the processing of mental data. If these procedures are adequate for simple reasonings, they are insufficient for complex reasonings. In our day-to-day we face a chaotic world which we have to interpret (decode) and organize within ou $\mathrm{B} / \mathrm{M}$ complex. Man must discover the world and organize it in his mind. Most of the time we are faced with fuzzy, vague, and contradictory data. The expert's competent statements attempt to avoid the spectrum of imprecision which surrounds the sciences of knowledge. Instead of ignoring or trying to eliminate imprecision, it is necessary to learn how to deal with it. Between our logical and non-logical reasoning there are shadow areas and even black holes. That is so because formal logic is based on syllogism, on deduction, on induction; formal logic is tautological and rests upon confirmation (deduction) or generalization (induction) of its premises. On the other hand, self-organizational logic [and even non-logical reasonings] develops by making errors, and from the errors it advances further, creating new developments and differentiated organizational structures ${ }^{23}$. In 1965, mathematician Zadeh ${ }^{39}$ elaborated a theory of non-formal logic, which he called diffuse or fuzzy logic. The rules of this logic vary according to the circunstances and, with the help of fuzzy sets and of the heuristics of imprecise theoretical sets, it is possible an approximation of the human reasonings forms. With this type of logic, which involves non-rigorous axioms, one 
can use inference chaining of the following type: in a first instance, 〈df a, then $b$ »; in a second instance, «if $a$, then not $b »$; in a third instance, «if $a$, then more or less $b$ »; and so on.

Now that we already know that imprecision and contradiction are not inconsistent with human reasoning, it is possible to suggest some molar mechanisms of the $\mathrm{B} / \mathrm{M}$ complex functioning. The mind attempts to decode the world to give it meaning and order: and by doing so, it tries to simplify the phenomena by using a decomposition mechanism, which is a reductionist one. It is one of the strategies of the $\mathrm{B} / \mathrm{M}$ complex in order to make its functioning operational, and it possibly is the computing aspect of the system. When the $\mathrm{B} / \mathrm{M}$ complex deals with number alone, it operates in a linear manner; however, when dealing with conceptual images, it tries to grasp the situation as a whole. The mind is projective when dealing with forms and, in a specific circumstance, by means of its gestaltic function (grasping of the whole), it is able to compose the situation again, even in the absence of certain elements. And the mind goes even further, for, according to Morin ${ }^{22}$, the brain functions are capable of finding a solution (heuristic competence), combining a set of decisions-choices (strategic competence), and making new combinations (inventive competence); in sum, the brain functions are capable to bring order from noise and to organize heterogeneous, proliferating, and disorganized mental data. This appears to be the computing/cogitant aspect of the $\mathrm{B} / \mathrm{M}$ complex.

Based on the concepts considered so far, we can divide thinking into two types: concrete and diffuse. Concrete thinking is supported by formal logic, and it attempts to be exact. It tries to eliminate error, disorder, ambiguity, imprecision, and contradiction from reasoning. Diffuse thinking, on the other hand, is approximative, fuzzy and attempts to deal with imprecision, contradiction, and the natural order/ disorder of things. It thies to think of order/disorder/organization simultaneously, by means of logical and non-logical processes. The model of concrete thinking is the computer with its ^binary reasoning». Whereas diffuse thinking looks for alternatives and, by means of constructive/unconstructive reasonings, it shows creative capacity. Both thinking models are complementary: concrete thinking is appropriate to make projects operational, while diffuse thinking is essential to the creative process. It can be stated that they act in complementary, competitive, and antagonistic ways ${ }^{23}$.

The operating way of the $\mathrm{B} / \mathrm{M}$ complex does not constitute simple epistemological speculation; it has many practical aspects to be considered by information science specialists who work in the field of artificial intelligence 13,33, Although human thinking cannot be rigorously put in mathematical terms, data-processing science also so-called informatique by trench's specialists (subsidized by other sciences) has relied upon logico-mathematical criteria to build the expert systems, and to try to build a machina sapiens. However, the model for construction of the intelligent machine» is the operating was of the $\mathrm{B} / \mathrm{M}$ complex, which does not always use logical processes. The role of the information science in artificial intelligence is to search for knowledge itsel (virtual knowledge), rather than to simply attempt a logico-mathematical formalization of knowledge ${ }^{33}$. The specialists' objective is to build knowledge models based on information science. But knowledge engineering encounters great difficulties in its attempts to provide solutions based on the algorithmic model for the problems of perception, reasoning and learning; with the contribution of the cognition sciences, one seeks complex heuristic models which may allow an approximation of human cognitive performance.

\section{CONCLUSIONS}

(1) The $\mathrm{B} / \mathrm{M}$ complex is an inseparable system which functions with emergent properties at various levels of hierarchical organization, irreducible to one another.

(2) The hierarchical organization levels are deeply integrated within an interactional plan, and are at least three: (i) the neuronal level, which has as its substratum nervous cells arranged according to the neurobiology of development; (ii) the functional level, which has as its substratum dynamic neurone networks whose configuration is provided by connectional mechanisms; (in) the conceptual level, based on a semantic network which deals with symbols within contexts.

(3) The B/M complex, which transforms information into meanings, deals with problems by means of both logical and non-logical mechanisms; while logic allows the mind to arrange the elements for reasoning, the non-logical mechanisms (fuzzy logic, heuristics, insights) allow the mind to develop strategies to find solutions 


\section{REFERENCES}

1. Alonso-Fernández F. Fundamentos de la Psiquiatria Actual. Madrid: Paz Montalvo, 1977, vol 1, p 543-551.

2. Andler D. Les sciences de la cognition. In Hamburger J (ed): La Philosophie des Sciences Aujourd'hui. Paris: Gauthier-Villars, 1986, p 131-167.

3. Bronowski J. Um Sentido do Futuro (Original title: A Sense of the Future: Essays in Natural Philosophy. Copyright 1977 by Massachuts Institute of Technology). Universidade de Brasília (without date), p 49-61.

4. Bronowski J. As Origens do Conhecimento e da Imaginação (Original title: The Origins of Knowledge and Imagination. Copyright 1978 by Yale University). Universidade de Brasília, 1985, pp 41-54.

5. Bunge M. The Mind-Body Problem: A psychobiological Approach. Oxford: Pergamon Press, 1980, p 1-31.

6. Changeux JP. L'Homme Neuronal. Paris: Fayard, 1983, p 275-330.

7. Dorozynski A. Les ordinateurs «neuronaux». Science \& Vie 1988, 854 : 117.

8. Edelman GM. Neural Darwinism: The Theory of Neuronal Group Selection. New York: Basic Books, 1987.

9. Feldman J, Ballard D. Connectionist models and their properties. Cog Science 1982, 6:205.

10. Fodor J. The Modularity of Mind: An Essay on Faculty Psychology. Cambridge: MIT Press/Bradford Book, 1983.

11. Geymonat L. Elementos de Filosofia da Ciência. Lisboa: Gradiva, (without date), p 3-24.

12. Gödel K. On Formally Undecidable Propositions. New York: Basic Books, 1962.

13. Haton JP. Intelligence artificielle: panorama des techniques et des domaines d'applications. In Le Moigne JL (ed): Intelligence de Mécanismes, Mécanismes de L'Intelligence. Paris: Fayard, 1986, p 57-73,

14. Hebb D. The Organization of Behavior. New York: Wiley, 1949.

15. Iwata M. Neural mechanism of reading and writing in the Japanese language. Funct Neurol 1986. 1:43

16. Le Moal M. Quelques aspects de la recherche biologique en psychiatric In Delacour J (ed): Neurobiologie des Comportements. Paris: Hermann, 1984 p 147-174.

17. Lima LO. A Construção do Homem Segundo Piaget. São Paulo: Summus, 1984, p 17-45.

18. Magoun HW. El Cerebro Despierto. Mexico: Prensa Medica Mexicana, 1964, p 1-19.

19. McCulloch WS, Pitts W. A logical calculus of the ideas immanent in nervous activity. Bull Math Biophys 1943, 5:113.

20. Mecacci L. Conhecendo o Cérebro. São Paulo: Nobel, 1986, p 31-41.

21. Minsky M. La Société de L'Esprit. Paris: InterEditions, 1988, p 351-369.

22. Morin E. O Enigma do Homem. Rio de Janeiro: Zahar, 1975, p 119-137.

23. Morin E. La Méthode 3. La Connaissance de la Connaissance/1. Paris: Seuil, 1986, p 47-67.

24. Popper KR, Eccles JC. The Self and its Brain. Berlin: Springer, 1977, p 425-566.

25. Pribam KH. Languages of the Brain. New York: Prentice Hall, 1975.

26. Pribam KH. Psicologia Científica Contemporânea. São Paulo: EPU, 1975, p 48-76.

27. Prochiantz A. La Construction du Cerveau. Paris: Hachette, 1989, p 47-73.

28. Riedl R. Biologia del Conocimiento: Los Fundamentos Filogenéticos de la Razón. Barcelona: Labor, 1983, p 209-227.

29. Searlé JR. Du Cerveau au Savoir. Paris: Hermann, 1985, p 15-36.

30. Sperry RW. Mentalism monism: consciousness as a causal emergent of brain processes Behav Brain Sci 1978, 3:367.

31. Sperry RW. Mind-brain interaction: mentalism, yes; dualism, no. Neuroscience 1980, $5: 195$

32. Sperry RW. Ciência e Prioridade Moral. Rio de Janeiro: Zahar, 1986, p 109-139.

33. Tiberghien G. Psychologie cognitive, science de la cognition et technologie de la connaissance. In Le Moigne JL (ed): Intelligence des Mécanismes, Mécanismes de L'Intelligence. Paris: Fayard, 1986 p 175-191.

34. Valdés AJ. Consciência, Conscienciacion y Fsico-socio-patologia. Valladolid: Universidade de Valladolid, 1985, p 87-134.

35. Varela FJ. Anatomie et Connaissance: Essai sur le Vivant. Paris: Seuil, 1989, p 17-31.

36. Varela FJ. Connaitre. Les Sciences Cognitives: Tendances et Perspectives. Paris: Seuil, 1989, p 53-87.

37. Vagotsky LS. A Formação Social da Mente. São Paulo: Martins Fontes, 1984, p 19-85.

38. Wang H. From Mathematics to Philosophy. London: Routledge \& Kegan, 1974,

39. Zadeh L. Fuzzy logic and approximative reasoning. Síntese 1976, 30 : 407. 